\title{
Tin Oxide Nanoparticles Produced by Spark Ablation: Synthesis and Gas Sensing Properties
}

\author{
ALEXEY EFIMOV ${ }^{1 *}$, IVAN VOLKOV ${ }^{1}$, ANDREY VARFOLOMEEV ${ }^{1,2}$, \\ ALEXEY VASILIEV ${ }^{1,2}$ and VICTOR IVANOV ${ }^{1}$ \\ ${ }^{1}$ Moscow Institute of Physics and Technology, Dolgoprudny, Moscow region, Russia. \\ ${ }^{2}$ NRC Kurchatov Institute, Moscow, Russia. \\ ${ }^{*}$ Corresponding author E-mail: efimov.aa @ mipt.ru \\ http://dx.doi.org/10.13005/ojc/320609
}

(Received: October 25, 2016; Accepted: December 05, 2016)

\begin{abstract}
The synthesis parameters and results of investigation of gas sensing properties of tin oxide nanoparticles produced by spark ablation are presented. The nanoparticles have sizes below 30 $\mathrm{nm}$ and their specific surface area is about $40 \mathrm{~m}^{2} / \mathrm{g}$. In order to study the gas sensing properties, a special structure comprising heater, barrier layers and contact pads was utilized. The resistance of the sensor fabricated on the basis of this structure was measured at different concentrations of hydrogen in the air (100-500 ppm) and different values of relative humidity (30-80\%). At working temperature of $450^{\circ} \mathrm{C}, 100 \mathrm{ppm}$ of hydrogen triggers more than 8-times decrease in the sensor resistance within the time interval of about $1 \mathrm{~s}$. At the same time, the humidity variation does not have pronounced effect on the sensor resistance: less than $30 \%$ in the humidity range studied.
\end{abstract}

Keywords: Tin oxide, Gas sensor, Spark ablation, Multi-spark discharge generator.

\section{INTRODUCTION}

Currently, the metal oxide semiconductor gas sensors are widely used for gas analysis ${ }^{1-4}$. They are relatively inexpensive compared to other sensing technologies and benefit from high material sensitivity and quick response times ${ }^{1,2}$. The operating principle of these sensors is based on the change in conductivity of the sensitive layer by the chemical adsorption of gas molecules ${ }^{3}$. Typically, the metal oxides semiconductors $\left(\mathrm{SnO}_{2}, \mathrm{In}_{2} \mathrm{O}_{3}, \mathrm{WO}_{3}, \mathrm{ZnO}\right.$, etc.) are used to create sensitive layers ${ }^{1,2}$. Traditional methods of synthesis of metal oxide gas sensing materials for semiconductor sensors are based on wet sol-gel processes ${ }^{2,4}$. However, these processes lead to the formation of hydroxyl groups on the surface of oxide particles being responsible for the strong response of a sensing material to the humidity ${ }^{3,4}$. In this regard, researchers are developing alternative methods of synthesis of nanoparticles such as the spark $^{5}$ and laser ablation ${ }^{6}$, flame synthesis ${ }^{7}$, electrical explosion of wire ${ }^{8,9}$, etc. In this group of methods, the spark ablation is probably the most promising method for the synthesis of 
chemically pure nanoparticles with a small size of primary particle less than $10 \mathrm{~nm}^{10}$.

In this work, the possibility of producing tin oxide nanoparticles by spark ablation was investigated. The gas sensing properties of the synthesized material were studied by using hydrogen as an analyte.

\section{EXPERIMENTAL}

The gas sensing material was synthesized by spark discharge. In this work, we used a custom- built multi-spark discharge generator ${ }^{11}$ containing 12 pairs of serially connected cylindrical electrodes powered by a 12-nF capacitor charged by a highvoltage source (Fig. 1). The electrodes made of pure tin (purity 99.95\%) with a nominal diameter of $6 \mathrm{~mm}$ were aligned axially at a distance of $0.5 \mathrm{~mm}$ and blown out continuously by the dry (relative humidity of $20-30 \%$ ) and clean air at a flow rate of $\sim 300 \mathrm{l} / \mathrm{min}$. The optimum values of the source output voltage and the pulse repetition frequency providing reasonable combination of the mean size $(<100 \mathrm{~nm})$ and the production rate $(>1 \mathrm{~g} / \mathrm{h})$ of airborne nanoparticles were found to be $4.5 \mathrm{kV}$ and $2.5 \mathrm{kHz}$, respectively.

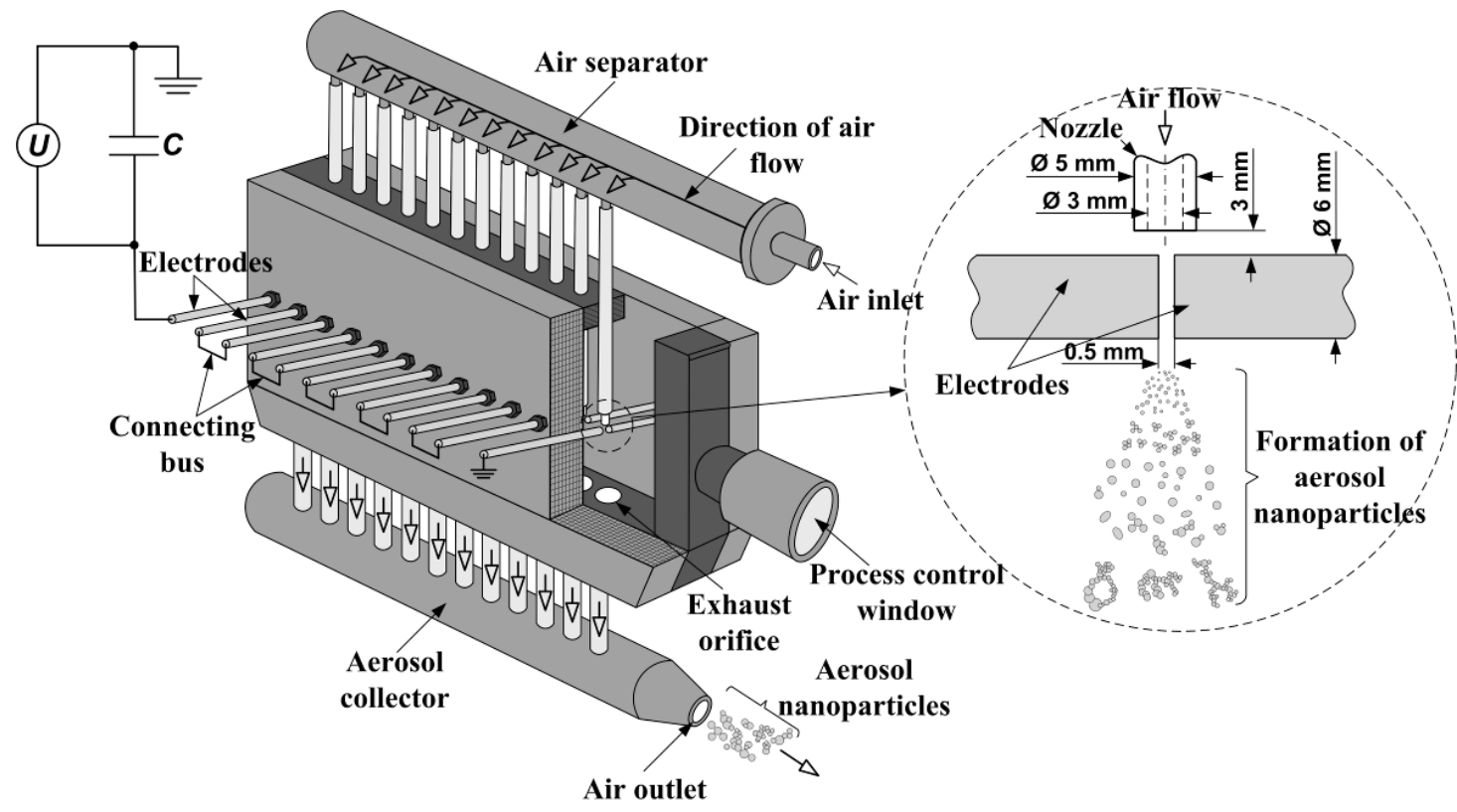

Fig. 1: Scheme of the multi-spark discharge generator

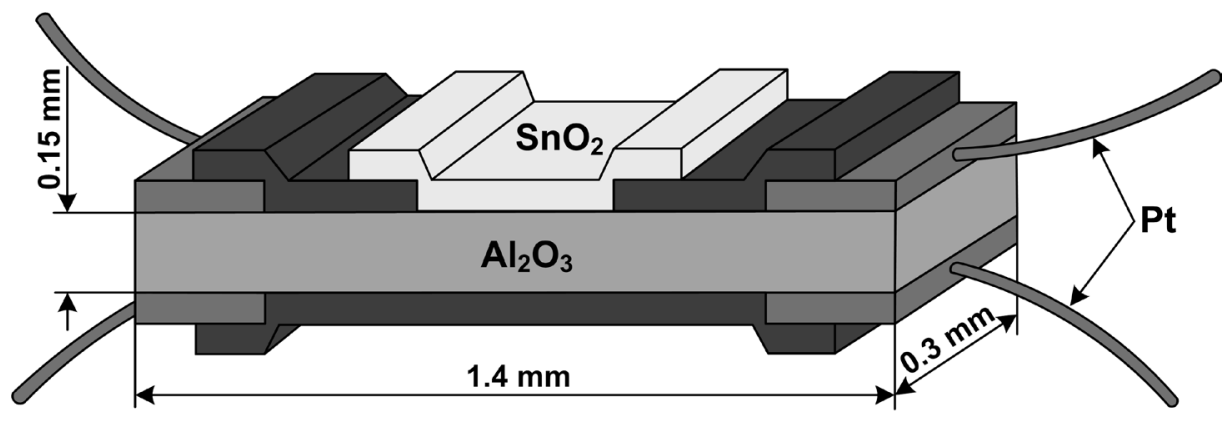

$\mathrm{SnO}_{2}$ sensing layer

Pt contact pads

$\square$ Heater and barrier layers

$\mathrm{Al}_{2} \mathrm{O}_{3}$ substrate

Fig. 2: Scheme of the gas sensor 
The airborne nanoparticles were deposited onto the air filter made of porous stainless steel. In order to reduce the metallic phase content, the assynthesized powder was annealed in air atmosphere as follows: 1) heating up to $610^{\circ} \mathrm{C}$ at a constant rate of $\sim 5 \mathrm{~K} / \mathrm{min}$.; 2) keeping $610^{\circ} \mathrm{C}$ for 2 hours.

The sensing ink was prepared by mortar mixing of pure $\mathrm{SnO}_{2}$ powder (without any catalyst decoration) with a solution of ethyl cellulose in terpineol. The ink droplet was deposited onto the sensor chip by dispensing. The ink was dried at $300^{\circ} \mathrm{C}\left(15 \mathrm{~min}\right.$.) and then fired at $720^{\circ} \mathrm{C}$ for 15 minutes. The scheme of the gas sensor is presented in Fig. 2. The gas detection mechanism of the sensor is based on the reversible change in the conductivity of $\mathrm{SnO}_{2}$ particles/grains induced by gas-solid interaction ${ }^{12}$.

The phase composition of produced materials was retrieved from $X$-ray diffraction (XRD) spectra measured with Bruker D8 DISCOVER. The particle size distribution was determined from transmission electron microscopy (TEM) images obtained with JEOL JEM-2100. The specific surface area was estimated by BET method with the use of Micromeritics TriStar 3000. Gas sensitivity was studied using Microgas-F setup.
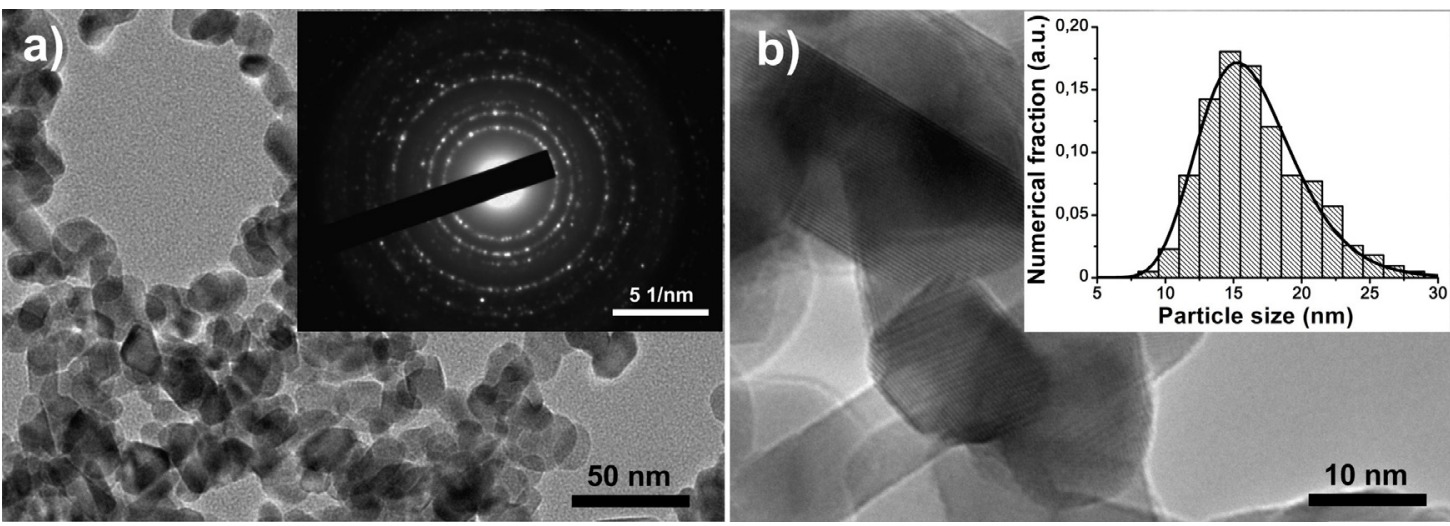

Fig. 3: TEM images of annealed nanoparticles at different magnifications (a and b), electron diffraction pattern (inset of figure a), and particle size distribution (inset of figure b)

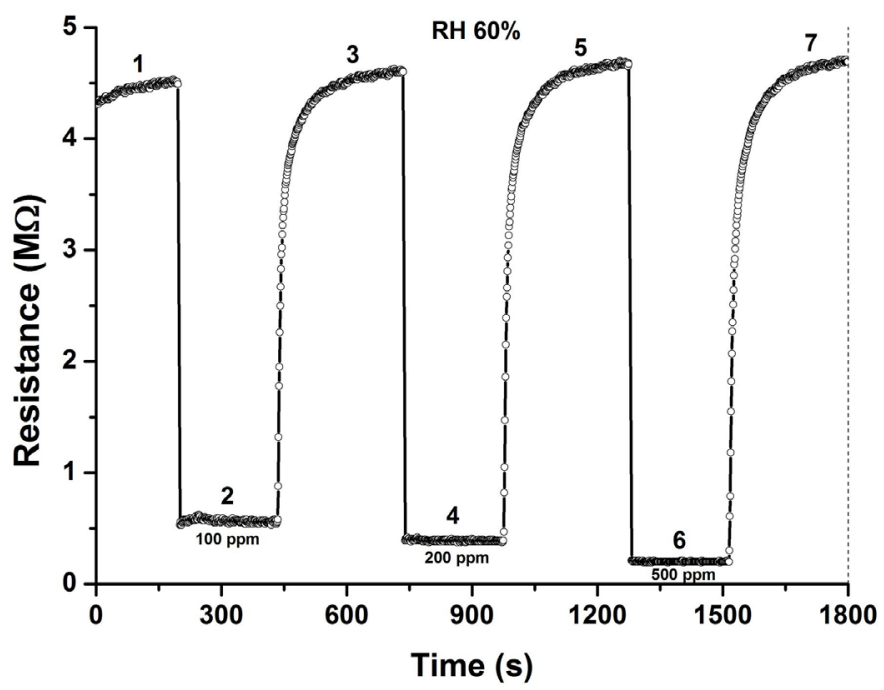

Fig. 4: Sensor response to different concentrations of hydrogen at $\mathrm{RH}=60 \%: 1,3,5$ and $7-$ air; 2, 4 and 6 - air with 100 ppm $\mathrm{H}_{2}$ 


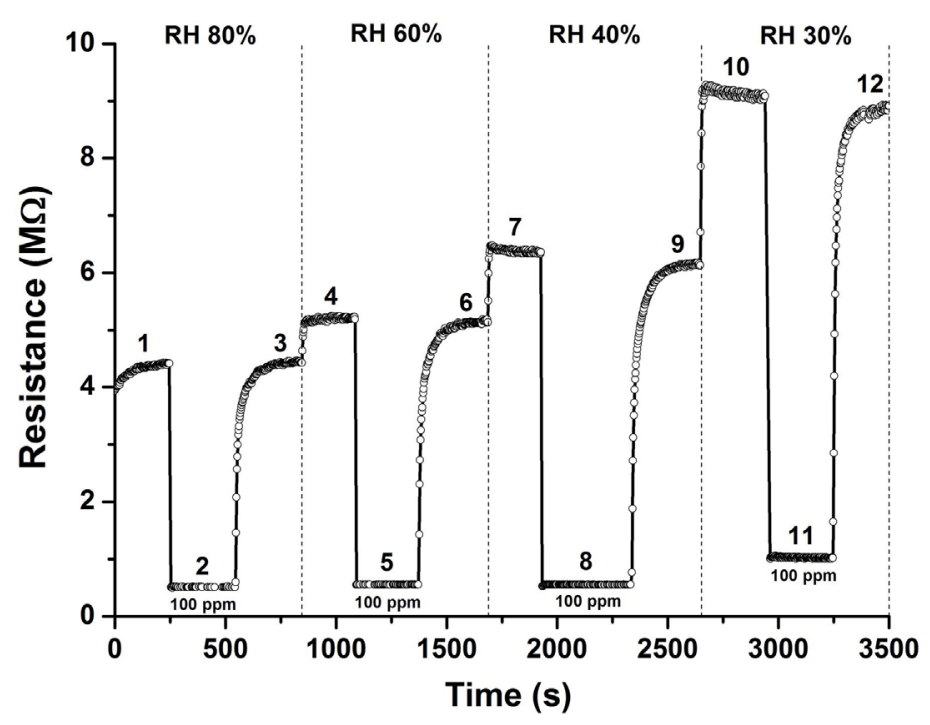

Fig. 5: Sensor response to $100 \mathrm{ppm}$ of hydrogen at different values of RH: 1 and $3-$ air at $\mathbf{R H}=$ 80\%; 2 - air with 100 ppm $\mathrm{H}_{2}$ at $\mathrm{RH}=80 \% ; 4$ and 6 - air at $\mathrm{RH}=60 \% ; 5$ - air with 100 ppm $\mathrm{H}_{2}$ at $\mathrm{RH}=60 \% ; 7$ and 9 - air at $\mathrm{RH}=40 \% ; 8$ - air with 100 ppm $\mathrm{H}_{2}$ at $\mathbf{R H}=40 \% ; 10$ and $12-$ air at $\mathbf{R H}=$ $30 \% ; 11$ - air with 100 ppm $\mathrm{H}_{2}$ at $\mathrm{RH}=30 \%$

\section{RESULT AND DISCUSSION}

It was found from XRD phase analysis that the annealed $\left(610^{\circ} \mathrm{C}\right)$ powder contains only $\mathrm{SnO}_{2}$ phase (> 98\%) and traces of unidentified phases. It is represented by near-spherical and slightly elongated particles (Fig. 3) possessing certain surface faceting. According to the electron diffraction patterns (insets of Figs. 3a), particles have a crystalline structure; it is also evidenced by TEM images at high magnification (Fig. 3b). The corresponding histogram is well described by log-normal distribution with the modal size of about $15 \mathrm{~nm}$ (inset of Fig. 3b). The specific surface area of nanoparticles is found to be about $40 \mathrm{~m}^{2} / \mathrm{g}$. These values are well correlated with the size parameters retrieved from TEM images.

Sensor resistance was studied for different concentrations of hydrogen in the air and relative humidity $(\mathrm{RH})$ of the air. Figure 4 shows the fast drop ( 1 s) and increase of resistance as response on turn on and off different hydrogen concentrations (100-500 ppm) in air flow at $\mathrm{RH}$ of $60 \%$. Figure 5 shows the response of resistance on turn on and off different relative humidity (30-80\%) in air flow with $100 \mathrm{ppm}$ of hydrogen. At working temperature of $450^{\circ} \mathrm{C}, 100 \mathrm{ppm}$ of hydrogen triggers more than 8-times decrease in the sensor resistance (Figs. 4 and 5). At the same time, the humidity variation does not have pronounced effect on the sensor resistance: less than $30 \%$ in the humidity range studied (Fig. 5). Fast response of the sensor to the humidity ( 10 s) and hydrogen $(\sim 1 \mathrm{~s})$ are observed in comparison with usual metal oxide sensors prepared by wet solgel processes.

\section{CONCLUSIONS}

The metal oxide gas sensing material $\left(\mathrm{SnO}_{2}\right)$ with a reduced sensitivity to water vapors was investigated. To decrease the concentration of $\mathrm{OH}$-groups, dry synthesis based on spark ablation of tin electrodes in air atmosphere was employed. The gas sensor based on this material demonstrated very fast and stable response. The response time to the humidity and hydrogen is about $1 \mathrm{~s}$ which is much shorter as compared to that of traditional sensor materials prepared by wet sol-gel processes. Thus, such materials are very perspective for the development of gas sensors for the fast detection of hydrogen in industry. 


\section{ACKNOWLEDGEMENTS}

This work was supported by the Russian

Science Foundation (project \# 15-19-00190).

\section{REFERENCES}

1. Barsan, N.; Koziej, D.; Weimar, U. Sens. Actuators B Chem. 2007, 121, 18-35.

2. Fine, G. F.; Cavanagh, L. M.; Afonja, A.; Binions, R. Sensors 2010, 10, 5469-5502.

3. Wang, C.; Yin, L.; Zhang, L.; Xiang, D.; Gao, R. Sensors 2010, 10, 2088-2106.

4. Gardon, M.; Guilemany, J. M. J. Mater. Sci. Mater. Electron. 2012, 24, 1410-1421.

5. Efimov, A.; Sukharev, V.; Ivanov, V.; Lizunova, A. Orient. J. Chem. 2015, 31.

6. Osipov, V. V.; Platonov, V. V.; Lisenkov, V. V. In Handbook of Nanoparticles; Aliofkhazraei, M., Ed.; Springer International Publishing, 2016; pp. 633-659.
7. Zolotko, A. N.; Poletaev, N. I.; Vovchuk, Y. I. Combust. Explos. Shock Waves 2015, 51, 252-268.

8. Ghorbani, H. Orient. J. Chem. 2014, 30, 1941-1949.

9. Kotov, Y. A. Nanotechnologies Russ. 2009, 4, 415-424.

10. Pfeiffer, T. V.; Feng, J.; Schmidt-Ott, A. AdV. Powder Technol. 2014, 25, 56-70.

11. Ivanov, V. V.; Efimov, A. A.; Mylnikov, D. A.; Lizunova, A. A.; Bagazeev, A. V.; Beketov, I. V.; Shcherbinin, S. V. Tech. Phys. Lett. 2016, 42, 876-878.

12. Liu, Y.; Koep, E.; Liu, M. Chem. Mater. 2005, 17, 3997-4000. 